\title{
MODELLING AND ANALYSIS OF HEAT TRANSFER MECHANISM OF A SOLAR HEATER COVER AND ABSORBER PLATE
}

\author{
A. O. C. Nwokoye \\ Department of Production Technology \\ (Physics Electronics Unit) Nnamdi Azikiwe University, Awka, Nigeria \\ E-mail:ositonyk@yahoo.com \\ Laz Ezenwaka, \\ Department of Industrial Physics Anambra State University, Uli, Nigeria
}

(Submitted: 30 October, 2007; Accepted: 14 February, 2008)

Abstract

\begin{abstract}
The analysis and the process by which heat transferoccurs between a solarheater cover and absorber plate as well as the analysis of radiative heat transfer mechanism are presented. The fluid motion is due to forced convection. Experimental and theoretical studies on the system's performance are also presented. The heated water temperature $T_{w}$ is recorded in the range $75^{\circ} \mathrm{C} 79^{\circ} \mathrm{C}$ in December, 2003 and in the range of $81^{\circ} \mathrm{C}-84^{\circ} \mathrm{C}$ in January, 2004. The peak temperature in each case was between $1200 \mathrm{hrs}$ and $1400 \mathrm{hrs}$ with a peak value at $1300 \mathrm{hrs}$. The systems radiative heat mechanism was found to be highly good. The result of the analysis of heat transfer mechanism of a solar heater cover together with the absorber plate show that it is very effective for domestic use. The result shows that the system remains very effective hence delivers heated water up to a maximum temperature of $84^{\circ} \mathrm{C}$.
\end{abstract}

Keywords: Solarheatercover, absorberplate, energy storage, food processing And solar radiation.

\section{Introduction}

Technical advances in solar water heating have been very rapid in the last 40 years. It has been of obvious benefits to house holders especially in those areas where the climate is ideally suited for the application of solar energy for water heating, particularly in the present situation of acute energy shortage. Solar water heaters find wide applications in large establishments such as hospitals, hotels, students hostels, industries including food processing, paper and textile, domestic uses and in heating swimming pools. The temperature requirement can easily be achieved with simple equipment, Garg and Prakash (2002). It is always advisable to use flat-plate collectors instead of concentrators in the development work. In the past years, almost all solar water heaters are based on the principle of flat-plate 
collector. Most pioneering work have been widely spread all over the world, including Europe, America, Asia, Caribbean and Africa.

The main objective of the experiment is to convert as much solar radiation as possible into heat at the highest attainable temperature and for the lowest possible investment in materials and labour.

Glass is an interesting cover material for solar thermal devices due to its ability to absorb almost all the infrared (IR) radiation re-emitted by the absorber plate. In effect it succeeds in creating a green house effect which enhances the thermal efficiency of the solar collector. This has been confirmed by Jannot and Coulibally (1997). The use of glass as a solar collector cover has two major disadvantages; the high cost Njomo (1995), and its fragile nature during its transportation and in service.

Transparent plastic covers (especially polyethylene) are used widely in developing countries in the rural areas because they are always available and can be used to construct moderate cost solar air heaters. Charters et al, (1989) and GRET (1986), have stated that these collectors are used mainly for foodstuff drying. The transmissivity of polyethylene to infrared radiation is $T_{\alpha}=$ 0.82 , Classen and Buttler (1980). The measurement of some temperature characteristics such as ambient, $T_{a}$, chamber, $T_{c}$ and water, $T_{w}$, of a solar water heater in addition to the average total solar radiation in $\mathrm{mJm}^{2} \mathrm{~d}$ were taken for Awka, Nigeria. In this paper, the radiative equations of the absorber plate, the transparent cover and heat transfer mechanism are examined. Malhortra et al (1981) stated that the glass and plastic materials of interest have refractive indices of 1.5 .

\section{Experimentation}

Two different experiments were carried out on two different periods, December 10, 2003 and January 17, 2004 and ambient, $T_{a}$, chamber, $T_{c}$ and water, $T_{w}$ temperatures, determined. The results are shown in Table 1 for 10 hours starting from 0800 hours to 1800 hours Another experiment was carried out

Table 1: Ambient temperature, $T_{a}$, chamber temperature, $T_{c}$, and water temperature, $T_{w}$, of a solar water heater measured on December 10, 2003 and January $17 ; 2004$.

\begin{tabular}{|l|c|c|c|c|c|c|}
\hline \multirow{2}{*}{ Time in hrs } & \multicolumn{3}{|c|}{ December 10,2003 } & \multicolumn{3}{c|}{ January 17,2004 } \\
\cline { 2 - 7 } & $\mathrm{T}_{\mathrm{a}}{ }^{0} \mathrm{C}$ & $\mathrm{T}_{\mathrm{c}}{ }^{0} \mathrm{C}$ & $\mathrm{T}_{\mathrm{w}}{ }^{0} \mathrm{C}$ & $\mathrm{T}_{\mathrm{a}}{ }^{0} \mathrm{C}$ & $\mathrm{T}_{\mathrm{c}}{ }^{0} \mathrm{C}$ & $\mathrm{T}_{\mathrm{w}}{ }^{0} \mathrm{C}$ \\
\hline 0800 & 27 & 34 & 37 & 28 & 35 & 41 \\
\hline 0900 & 28 & 45 & 50 & 29 & 48 & 55 \\
\hline 1000 & 29 & 50 & 65 & 30 & 55 & 67 \\
\hline 1100 & 31 & 61 & 73 & 32 & 62 & 75 \\
\hline 1200 & 33 & 65 & 80 & 34 & 68 & 81 \\
\hline 1300 & 35 & 76 & 83 & 36 & 79 & 84 \\
\hline 1400 & 38 & 73 & 77 & 39 & 75 & 80 \\
\hline 1500 & 35 & 70 & 74 & 37 & 72 & 78 \\
\hline 1600 & 32 & 67 & 70 & 33 & 68 & 75 \\
\hline 1700 & 29 & 62 & 66 & 31 & 64 & 71 \\
\hline 1800 & 28 & 59 & 62 & 28 & 61 & 65 \\
\hline
\end{tabular}

Nigerian Journal of Physics, 20(1),2008 
the means of the monthly maximum water temperature reached in the solar heater determined, the ambient temperature $T_{a}$ as well as the temperature of the system, (absorber) $\mathrm{T}_{\mathrm{s}}$ and the total radiation $\mathrm{H}_{\mathrm{o}}$ on horizontal surface at Awka, Nigeria, $\left(6.12^{\circ} \mathrm{N}\right.$, $7.05^{\circ} \mathrm{E}$ ) were also determined. The means of the monthly maximum, proposed by Klein, (1977) was used. In the proposal, Klein suggested using dn for the mean day of the month, hence the equivalent $n$ to be used is shown in Table 2, and in equation (1) for the year 2004. The Linke Feussner pyrheliometer was used to measure the monthly average of the total solar radiation $\mathrm{H}_{0}$ in $\mathrm{mJ} / \mathrm{m}^{2} \mathrm{~d}$ for January 17 , 2004. The results are recorded in Table 2.

Table 2: Monthly mean solar radiation parameters and the mean of maximum ambient temperature, $T_{a}$, and system temperature, $T_{s}$, of a solar water heater measured in 2004.

\begin{tabular}{|c|c|c|c|c|c|c|c|c|}
\hline $\begin{array}{l}\text { Monthly } \\
\text { average, } \\
d_{n}\end{array}$ & $\mathbf{N}$ & $\begin{array}{c}\text { Declination } \\
\quad \partial\end{array}$ & $\begin{array}{l}\text { Hour } \\
\text { angle } \\
w^{\circ}\end{array}$ & $\begin{array}{l}\text { Hour } \\
\text { angle } \\
\text { radian }\end{array}$ & $\mathrm{T}_{\mathrm{a}},{ }^{\circ} \mathrm{C}$ & $\mathrm{T}_{8},{ }^{\circ} \mathrm{C}$ & $\begin{array}{l}\text { Average } \\
\text { Total Solar } \\
\text { radiation } \\
\mathrm{H}_{0} \text { in } \\
{\mathrm{MJ} / \mathrm{M}^{2}-\mathrm{d}}\end{array}$ & $\epsilon_{0}$ \\
\hline Jan. 17 & 17 & -20.92 & 87.65 & 1.533 & 37 & 77 & 43.02 & 1.0300 \\
\hline Feb. 16 & 47 & -12.95 & 88.59 & 1.546 & 35 & 75 & 43.00 & 1.0251 \\
\hline Mar. 16 & 75 & -2.42 & 74.96 & 1.308 & 33 & 71 & 39.11 & 1.0108 \\
\hline April 15 & 105 & 9.41 & 91.02 & 1.589 & 31 & 69 & 34.98 & 0.9938 \\
\hline May. 15 & 135 & 18.79 & 92.09 & 1.607 & 30 & 66 & 28.99 & 0.9780 \\
\hline June 11 & 162 & 23.09 & 92.49 & 1.614 & 30 & 64 & 25.47 & 0.9692 \\
\hline July. 17 & 198 & 21.18 & 92.38 & 1.613 & 29 & 63 & 25.33 & 0.9674 \\
\hline Aurg. 16 & 228 & 13.45 & 91.47 & 1.597 & 31 & 65 & 28.98 & 0.9746 \\
\hline Sept. 15 & 258 & 2.22 & 90.24 & 1.575 & 31 & 67 & 34.27 & 0.9885 \\
\hline $0 c t 15$ & 288 & -9.60 & 88.96 & 1.553 & 32 & 70 & 38.68 & 1.0058 \\
\hline Nov. 14 & 318 & -18.91 & 87.89 & 1.534 & 33 & 73 & 40.94 & 1.0222 \\
\hline Dec. 10 & 344 & -23.05 & 87.39 & 1.525 & 34 & 75 & 41.83 & 1.0319 \\
\hline
\end{tabular}

The eccentricity correction factor $\epsilon_{\text {o }}$ equivalent for the average days are recorded and given from a more detailed expression, (Duffie and Beckman, 1991).

\section{Theory}

Garg and Prakash (2002) had proposed that for the average total solar radiation, the appropriate equation is given by

$$
H_{0}=\underline{24} I_{s c}(1+0.33 \operatorname{Cos} \underline{360} n) \quad X
$$


$(\operatorname{Cos} \Phi \operatorname{Cos} \partial \operatorname{Sin} \omega+\omega \operatorname{Sin} \Phi \operatorname{Sin} \partial)(1)$ where Isc is the equivalent solar constant given by $4921 \mathrm{~kJ} / \mathrm{m}^{2} \mathrm{hr}$ and $\partial$ is the sun's declination Cooper (1969), has given the sun's declination equation as

$$
\partial=23.45 \sin \left\{\frac{360}{365}(284+d n)\right\}
$$

\section{Performance Prediction of Solar Water Heater}

Zallner et al. (1985) stated that thermal optimization of built-in-storage water heater must be based on the evaluation of system performance under diverse conditions. The instantaneous heat balance as illustrated in Fig. 1 according to Garg (1975), may be written in the form: radiation absorbed $=$ heat absorbed by water + heat absorbed by container + heat loss from the absorber. It is assumed that for practical purposes (under steady state conditions) that the water temperature is equal to the absorber temperature, hence $T_{\omega}=T_{c}$ and

$$
\frac{\mathrm{dT}}{\mathrm{dt}} \omega-\frac{\mathrm{dT}}{\mathrm{dt}}
$$

Equation (4) thus becomes

$X \frac{\mathrm{dT} \omega}{\mathrm{d}} \omega+\mathrm{YT}_{\omega}=\mathbf{Z}$

where $X=W_{\omega}+W_{c}+$

$\left(U_{\mathrm{L}}+\mathrm{U}_{\mathrm{B}}\right) \mathrm{A}_{\mathrm{C}} / 2$

$Z=I T_{i}\left(T_{a}\right) A_{c}+\left(U_{L}+\right.$

$\left.\mathrm{U}_{\mathrm{B}}\right) \frac{\mathrm{A}_{\mathrm{C}}}{2}\left[\frac{\mathrm{dT} \mathrm{a}}{\mathrm{dt}}+2 \mathrm{Ta}\right)$

The solution to eqn. (5) is

$T_{\omega}=\frac{Z}{Y}+\left(T_{\omega \mid} \frac{Z}{Y} \exp \left(\frac{-Y}{X}\left(t t_{1}\right)\right)\right.$

where $T_{\omega 1}$ is the initial water temperature at time $t_{1}$, when fresh water is added.

The radiative heat transfer equation $\mathrm{hr}_{1}$ from plate to cover were shown by Sukhame (1984), Williams (1983), with hour angle as

$\omega=\operatorname{Cos}^{-1}(-\tan \Phi \tan \partial)$

where $\Phi$ is the latitude location of the place.
Garg (1982) as well as by Whillier and Saluja (1964) as

$\mathrm{hr}_{1}=\frac{\sigma \mathrm{T}_{\mathrm{p}}^{2}+\mathrm{T}_{1}^{2}\left(\left(\mathrm{~T}_{\mathrm{p}}+\mathrm{T}_{1}\right)\right.}{\left(1 / \epsilon_{\mathrm{p}}+1 / \epsilon_{1}-1\right.}$

where $\sigma$ is Stefan - Boltzmann's constant, $T_{P}$ is the temperature of the plate, $T_{1}$ is the cover temperature, $\epsilon p$ is the emissivity of the plate and $\epsilon_{1}$ is the cover emissivity respectively. Also the radiative heat loss from plate to cover is given by

$$
H r_{p}=\frac{\sigma T p^{2}+T_{1}^{2}\left(\left(T_{p}+T_{1}\right)\right.}{\left(1 / \epsilon p+1 / \epsilon_{1}-1\right.}
$$

It is also noted that if the depth or distance between upper and lower plates of the system increases, the collector efficiency increases since the thermal losses to the outside air decreases.

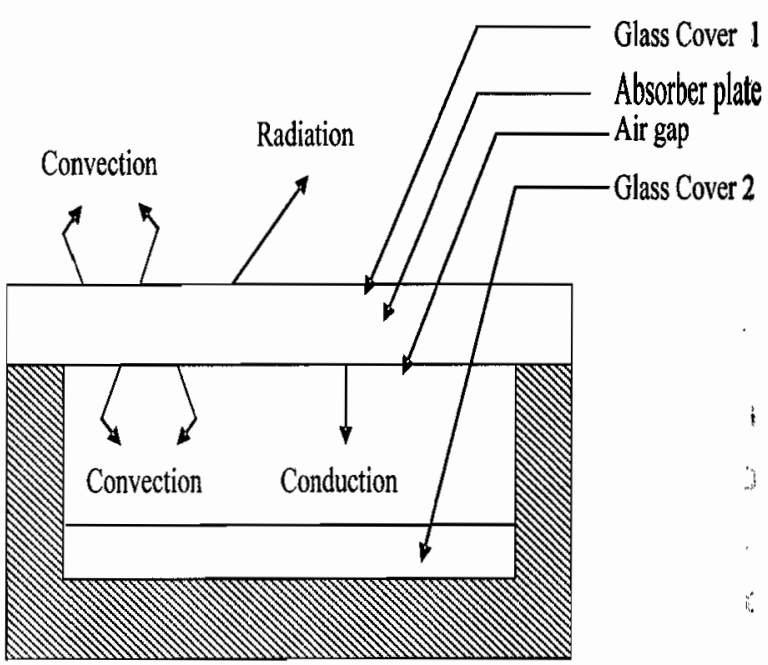

Fig. 1: Illustration of built-in-storage type solar water heater. 


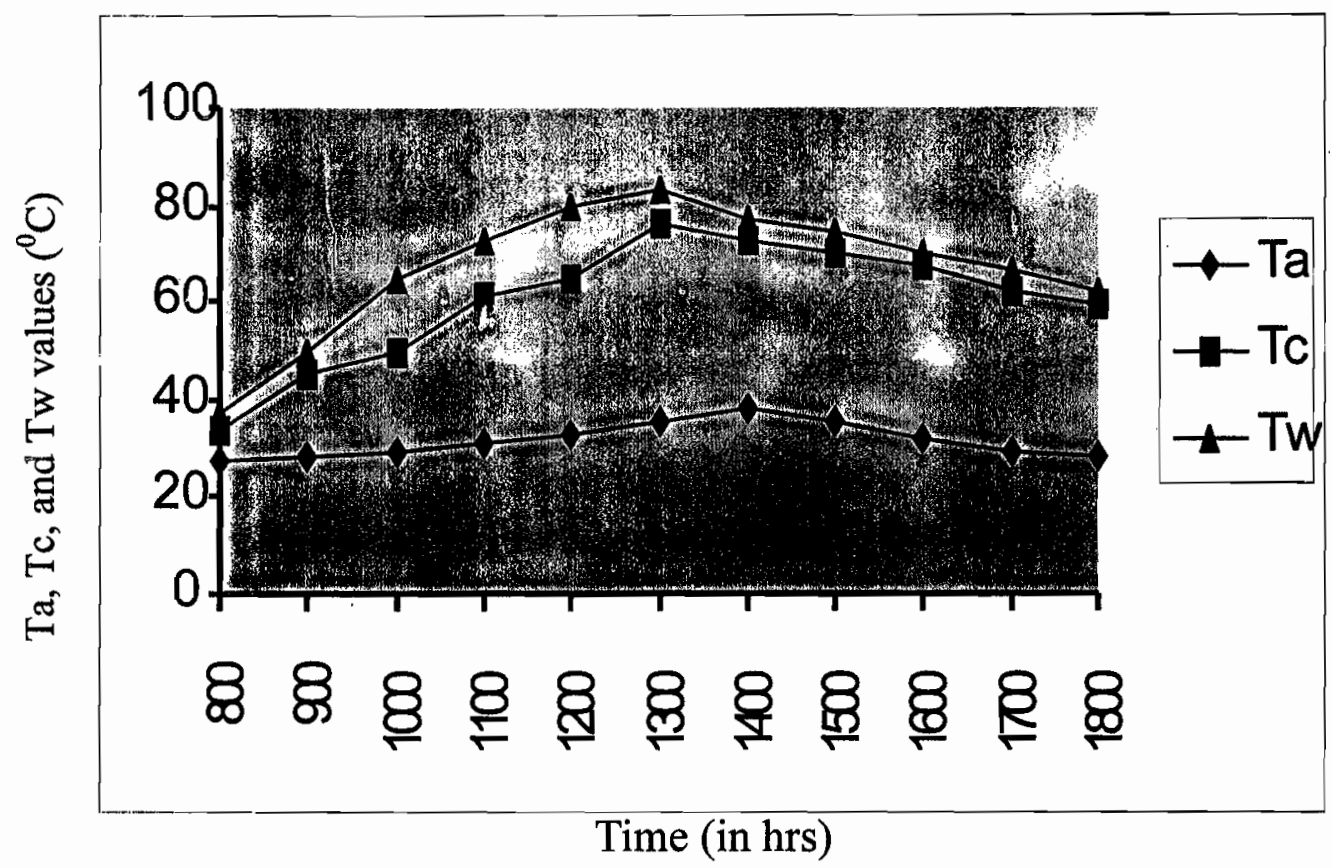

Fig. 2: Hourly variation of ambient temperature Ta, chamber temperature Tc, and water temperature Tw of a solar water heater on December 10, 2003.

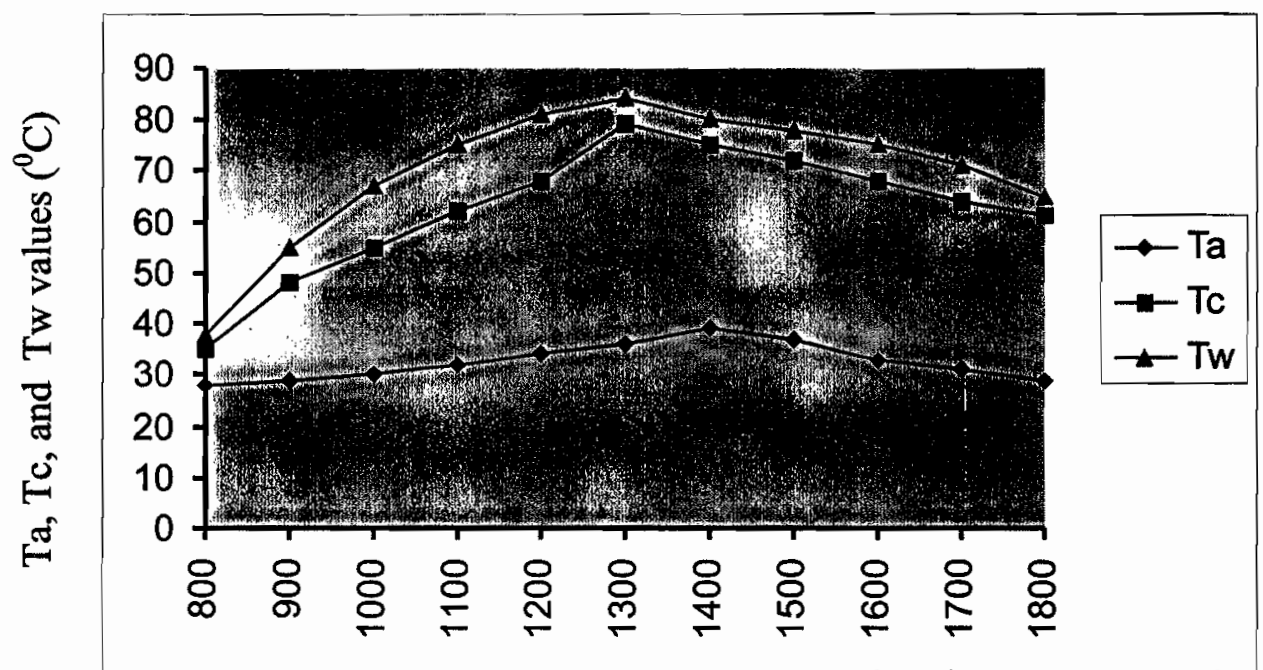

Time (in hrs)

Fig. 3: Hourly variation of ambient temperature $\mathrm{Ta}$, chamber temperature $\mathrm{Tc}$, and water temperature, Tw of a solar water heater on January 17, 2004. 


\section{Results and Discussion}

Results show that the monthly average of the daily maximum temperature of the water in the solar heater lies in the range $71^{\circ} \mathrm{C}-77^{\circ} \mathrm{C}$ in the month of January to March 2004 and in the range $70^{\circ} \mathrm{C}-75^{\circ} \mathrm{C}$ from October to December of the same year, Table 2 .

In Table 1, various values of ambient temperature $\mathrm{Ta}$, collector temperature $\mathrm{Tc}$, and water temperature Tw show that the temperatures were in steady rise until it attained maximum at 1300 hours after which the values steadily decreased as the sun's declination disappear. A maximum temperature of $84^{\circ} \mathrm{C}$ was attained for the system. In Table 2, the various measured values of average total solar radiation in $\mathrm{mJ} / \mathrm{m}^{2} \mathrm{~d}$ are shown. Maximum and minimum values were attained in the month of January, 2004. This gradually decrease started rising again steadily in the month of October. The systems temperatures were also found to be high in the months with high average total solar radiation and at the same time low in the months with low average total solar radiation. The graphical illustration in Figs. 2 and 3 each show the variation of the measured ambient temperature $T_{a}$, chamber temperature $T_{c}$ and water temperature $T_{w}$ for December 2003 and January, 2004 respectively. The peak temperature in each case was between $1200 \mathrm{hrs}$ and $1400 \mathrm{hrs}$ with the peak value at $1300 \mathrm{hrs}$. The ambient temperature $T_{a}$ in each case was found to be lowest. It was also observed that while Fig. 4 shows the monthly average of the daily maximum of the measured ambient temperature $\mathrm{T}_{\mathrm{a}}$ and system temperature $\mathrm{T}_{\mathrm{s}}$, Fig. 5 shows the variation of the monthly average total solar radiation $H_{0}$ for 2004

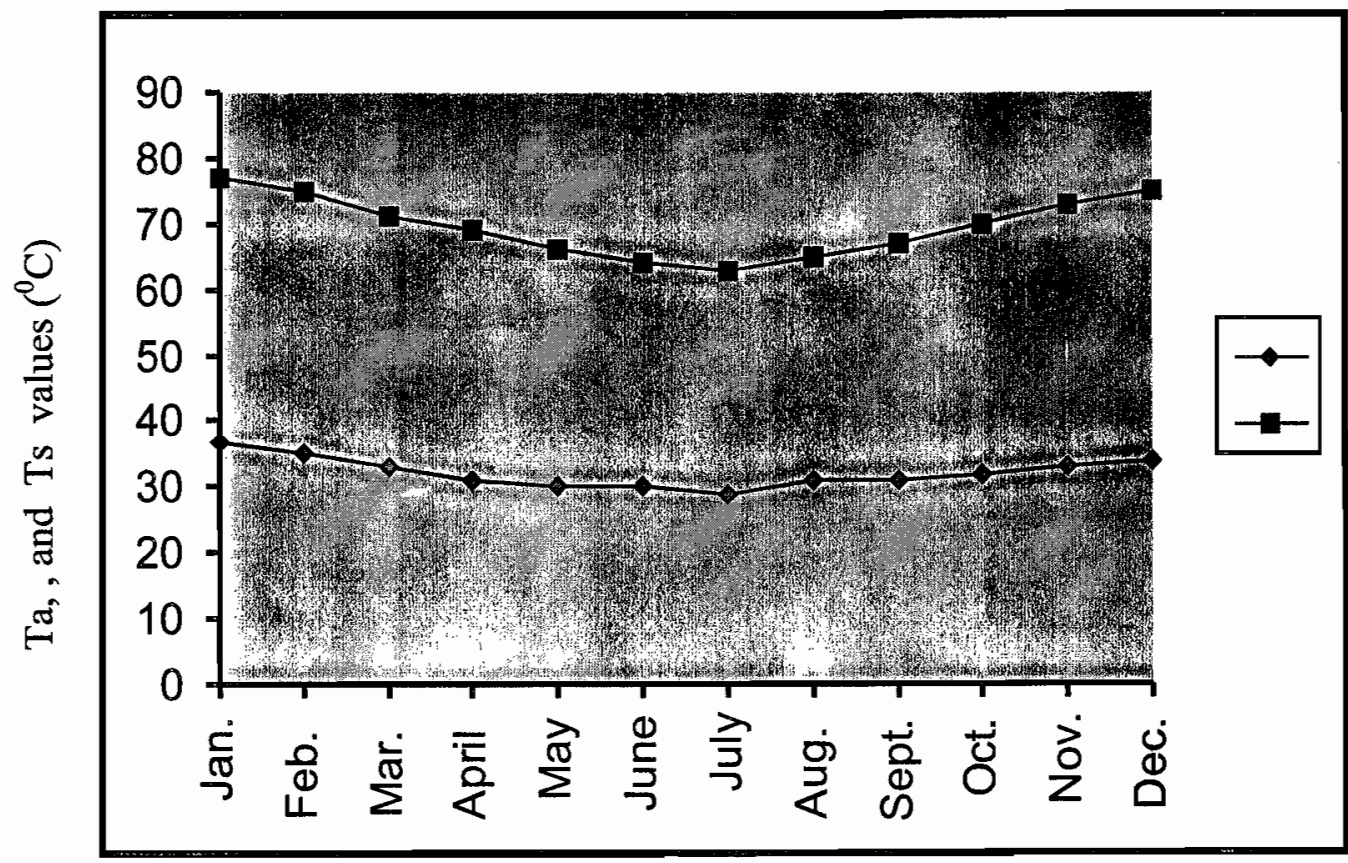

Months of the year

Fig. 4: Monthly average of the daily maximum of ambient temperature, Ta, and systems (absorber) temperature, Ts, of a solar water heater measured in 2004. 


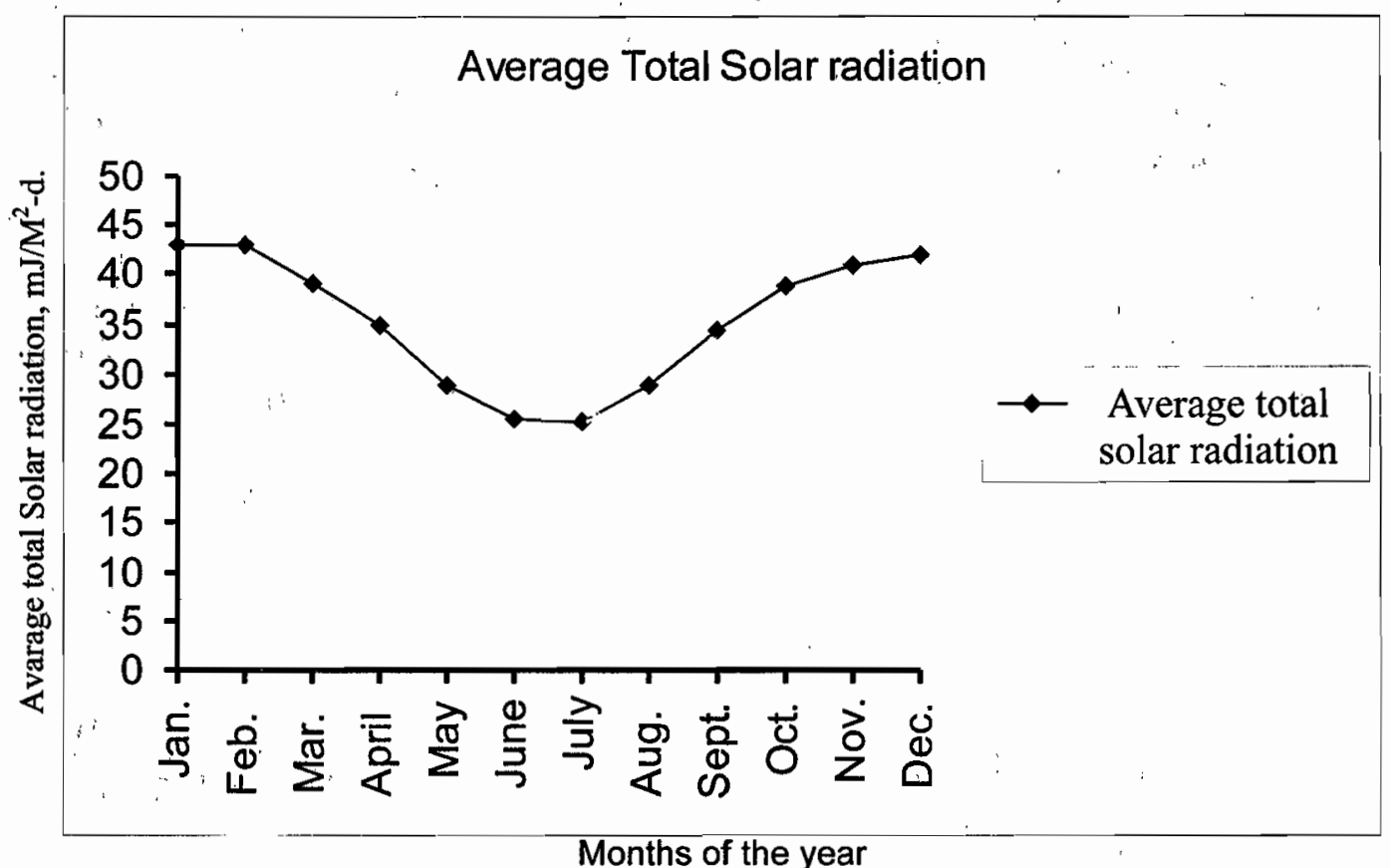

Fig. 5: Variation of monthly average total solar radiation $\mathrm{H}_{\mathrm{o}}$ for 2004 .

\section{Conclusion}

The systems radiative heat mechanism was found to be highly good. The results show that hot water temperature varied from $71^{\circ} \mathrm{C}$ to $77^{\circ} \mathrm{C}$ in the months of January to March, 2004 and $70^{\circ} \mathrm{C}$ to $75^{\circ} \mathrm{C}$ in the months of October to December of the same year. The results are confirmed to be in line with that of Garg and Prakash (2002). The result of the analysis of heat transfer mechanism of a solar heater cover together with the absorber plate has supported the use of solar energy for domestic purposes. The results of the average total solar radiation $\mathrm{H}_{0}$ obtained in the experiment was in line with that obtained by Garg (1975) and Zallner et al. (1985).

\section{References}

Charles, W. W. S, Macdonald, R. W.

G., Kaye, D. R. and Xiaorem Sun, (1989): Passive Green House Type Solar Dryers and their Development, RERIC Int.
Energy J., 11, 51-60.

Classen, R.S. and Buttler, B.L.

(1980): Introduction to Solar Materials Science; In Solar Material Science, chapter 1. Academic Press, New York, 351.

Cooper, P.I. (1969): The Absorption of Solar Radiation in Solar Stills, Solar Energy, 12, 3.

Duffie J.A. and W. A. Beckman (1981): Solar Engineering of Thermal processes John Willey, New York.

Garg, H.P. and Prakash, J. (2002): Solar Energy, Fundamentals and Applications, Tata. McGraw-Hill publishing Company Limited, New Delhi.

Garg, H.P. (1982): treatise on Solar Energy, John Willey, New York. Garg, H.P. (1975): Year Round 
Performance Studies on a Builtin-storage Type Solar Water Heater at Jodhpur, India, Solar Energy, 17, 167-172.

GRET (1986): Le Point Sur Le Sechage

produits alimentaires, GRET, Paris.

Yves I. Jannot and Yezouma Coulibally (1997): Radiative Heat Transfer in a Solar Air Heater Covered with a Plastic Film, Solar Energy $60(1), 35$.

Malhortra, A., Garg, H. P. and Palit, A. (1981): Heat Loss Calculations of Flat Solar Collector, J. Thermal Energy 2(2).

Njomo, D. (1995): Techno-economic

Analysis of a Plastic Cover Solar Air Heater, Energy Convers. Mgmt, 36, 1023-1029.
Klein, S.A. (1977): Calculation of Monthly Average Isolation on Tilted Surfaces, Solar Energy, 19, 325.

Williams, J. R. (1983): Design and Installation of Solar Heating and Hot Water Systems, Ann Arbor Science, Michigan.

Wihillier, A. and Saluja, G. (1965): The Thermal Performance of Solar Water Heaters, Solar Energy $9(1), 21$.

Sukhame, S. P. (1984): Solar Energy, Tata McGraw Hill, New Delhi.

Zallner, A; Klein, S.A. and Beckman, W.A. (1985), A Performance Prediction Methodology for Integral Collector-Storage Solar Domestic Hot Water Systems; trans. ASME, J. Solar Energy Engg., 107, 265. 